\title{
Investigation quantitative traits in modified Iranian 'Red Rey' onion (Allium cepa L.) and comparison with primary mass selection and 'Red Azar-shahr' cultivar
}

\author{
S.M.T. Shokrgozar ${ }^{1}$, M. Khodadadi ${ }^{2}$, V. Abdossi ${ }^{1}$, V. Zarrinnia ${ }^{3}$ and R. Hajiyanfar ${ }^{2}$ \\ ${ }^{1}$ Department of Horticultural Sciences, Islamic Azad University, Science and Research Branch, Tehran, Iran \\ ${ }^{2}$ Vegetable Research Centre, HSRI, Agricultural Research Education and Extension Organization, Iran \\ ${ }^{3}$ Department of Plant Protection, Science and Research Branch, Islamic Azad University, Tehran, Iran
}

\section{Summary}

The purpose of this two-step research during 2012-2016 was to investigate quantitative traits of bulb in 'Red Rey' Iranian modified onion (Allium cepa $\mathrm{L}$.) population. At first, the modified population was achieved by the selection of superior bulbs, cultivation, its self-pollination and consequently the identification of the best families, and implement open pollination between them. Next step, the 'Red Rey' Iranian modified population with basic population and 'Red Azar-shahr' improved cultivar (as a comparative cultivar) were crossed in randomized complete block design (RCBD) at three replicates and the different traits were measured. Our finding indicated that the selection method has led to improvement in many characters of this population. The results obtained could be summarized as follows: The mean of yield, early maturity and bulb uniformity among 100 selected families show that the $68,94,6,56$ and 57 are the best families in terms of statistical rank. Modified 'Red Rey' Iranian relieved number of leaves 9, dropping off plants $91.4 \%$, yield 69.68 tons ha $^{-1}$, bulb weight $173.5 \mathrm{~g}$, bulb neck diameter $10.92 \mathrm{~mm}$, whereas percentage of twins, bulb diameter and bulb height of 'Red Azar-shahr' were slightly more than that of modified 'Red Rey' cultivar. Number of layers and number of bulb centers was not affected by genotype. Regarding to these, the present technique illustrates an effective system for selection of superior bulbs. In addition, it proved to be effective in improvement in this plant.

Keywords

'Red Rey' onion cv., yield, early maturity, neck diameter, breeding, 'Red Azar-shahr' cv.

\section{Introduction}

Onion (Allium cepa L.) is a monocot plant belonging to the family Alliaceae, which is the third most important cultivated vegetable crop with a global yield of dry bulbs of 88 million tons (Anonymous, 2015). Iranian onion is exported including fresh white, red, and yellow onion with the taste ranges from mild and sweet to sharp and spicy, depending on the kind and season. They are delicious and full of flavour, with a fresh and firm texture, making it acceptable by households, restaurants, hotels, etc. Because of nativeness,

\section{Significance of this study}

What is already known on this subject?

- Description of quantitative features of Allium cepa L. and compared to primary mass selection and control population.

What are the new findings?

- The selection procedure has led to refinement in many useful traits of this population such as bulb uniformity, bulb neck diameter, and percentage of twins.

What is the expected impact on horticulture?

- Selection of superior bulbs can be an effective step towards achieving improvement in marketingcompatible horticulture.

cultivation and cross-pollination history, Iranian onion has very rich varieties/cultivars and genetic reserves. They are mainly produced with long-day populations and cultivars in autumn. Traits of native populations are often undesirable due to their genetic erosion and frequent cultivation so that the improvement of native varieties/cultivars is a first priority. In Tehran and Alborz provinces, 'Rey' population is often cultivated in an area of about 1,000 hectares. The results of previous experiments with 5 'Rey' morphotypes, along with 18 morphemes from three major populations of the country ('Red Azar-shahr', 'Red Rey' and 'Zanjan Qalb'), were investigated in terms of different traits (Moussavizadeh et al., 2006a). All morphotypes of 'Red Rey' population, especially No. 13, had high status in terms of yield per hectare and bulb dry matter. The non-uniformity, time of maturity and relative thickness of the bulb neck have been found a major problem for the population, which required the cultivar improvement (Moussavizadeh et al., 2006b).

Local populations in vegetables such as onions are always considered as an important gene bank for breeding programmes. Onion populations have a high degree of heterozygosis that persists through amphimixis (Dowker, 1990). It is essential to make an accurate selection of native bulbs when seeds are produced to maintain the desired traits. Improvement has been done for traits such as quality, yield, uniformity, resistance to diseases, adaptation to different latitudes, and agronomic operations (Jones and Mann, 1963; Pike, 1986). Historically, the method of selecting pollinatorfree populations or segregated families has been considered, although using a periodic selection method-breeding, yield 
can be achieved (Dowker et al., 1984; Havey and Randle, 1996). In the United States, three synthetic varieties of onion were produced from a series of in-bred, yellow-brown, highpungency, high-volume, and well-stored lines consistent with New York conditions. In addition, in the second series, six new synthetic varieties were improved (Goldschmied et al., 2004).

In species of the genus Allium, the heritability estimates and high genetic yield were reported for onion weight, leaf length, leaf number, onion length and onion diameter (Kalloo et al., 1982; Abayneh, 2001). Degewione et al. (2011) estimated the yield of single-plant heritability as medium to very high. Hosamani et al. (2010) investigated high heritability in dry matter content $(30.80 \%)$, yield per hectare $(63.79 \%)$, soluble solids (24.74\%) and mean onion weight (64.64\%).

Increasing yield per unit area is one of the important goals of onion breeding. The yield is a quantities trait that depends on a number of traits and is influenced by genetic and environmental factors. Mousavizadeh et al. (2006b) reported a positive and significant correlation between onion diameter, onion length, leaf length, and number of leaves per plant of onions. The diameter of onion had the most direct positive effect on the yield of onion single plant. Onion length and leaf length also had a direct effect on the yield of onion single plant. The most indirect effect of leaf number was applied through onion diameter.

In a study of Darabi (2005), the local population breeding was carried out in Behbahan Agricultural Research Station by the method of producing pollinator-free cultivars from 1999. In the first year, the selected bulbs' storage was checked and then two in-bred generations were made. Then, two generations free pollination were separated among the selected plants. After completing the breeding stages, the most suitable planting date and plant density were determined for

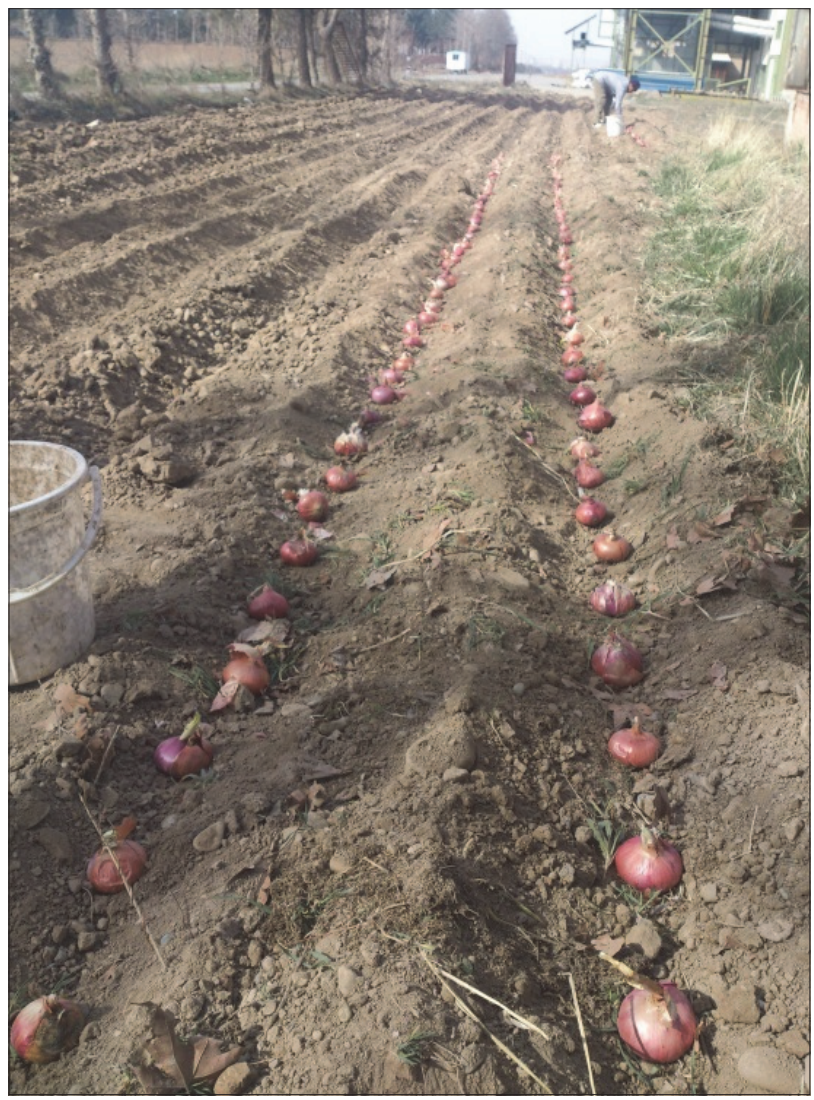

FIGURE 1. 500 bulbs of 'Red Rey' cultivar were cultured. the improved population in a breeding project. Adaptation of this genotype was studied for the southern short-day regions. In addition, this genotype was evaluated under cultivation conditions. The obtained results showed that if the planting date and suitable density were observed, this genotype had a high production potential (total and salable yield 69.34 and 60.26 tons ha $^{-1}$ respectively and given the white color and high percentage of the dry matter, the bulb is suitable for processing. The mentioned genotype has a long shelf life and is desired in terms of uniformity in the shape and color of the bulb. Regarding to total and salable yield, the percentage of twinning and purity of color was superior to the population of origin under cultivation conditions. The study results on Iranian onion cultivars such as 'Red Rey' showed that this population has a relatively high storage potential. It is later mature than 'Red Azar-shahr' and 'Qom white' populations (Khodadadi and Rastegar, 1999). Compared to the populations of Zanjan Province, this has superior yield and dry matter (Manbachi and Khodadadi, 2011).

Therefore, this research was carried out with the aim of studying modified 'Red Rey' population as for reducing neck diameter, and developing early maturity, with maintaining and improving total yield.

\section{Materials and methods}

Experiments were conducted during 2012-2016 at the experimental field of Seedling and Seed Breeding Institute of Karaj, located at $35.48^{\circ} \mathrm{N}, 50.58^{\circ} \mathrm{E}$. At first stage, Seed Morphotype No.13, as the best among the 'Red Rey' morphotypes was cultivated at $500 \mathrm{~m}^{2}$ in spring 2012 (base population). Suitable bulbs were harvested up to 500 bulbs according to the type of 'Red Rey' cultivar and they were stored in the cold store $\left(5^{\circ} \mathrm{C}\right.$ with $50-70 \% \mathrm{RH}$ ) (October 2012), then they were planted in early March 2013 (Figure 1). Irrigation, nutrition and weed control in fields were employed during April and May (2013) for maximum productivity. 300 superior plants were selected on the basis of specific parameters, i.e., vegetative growth and seedling diameter, and then cages and netting were created on them for self-pollination (late June 2013). Self-pollinated seeds were collected separately from each branch and kept in Vegetable and Legume Section, Agriculture Research Center, Karaj, Iran. It should be noted that only 100 plants produced enough seeds, which are adequate to continue the study (One plant row ${ }^{-1} \times 100$ rows $=100$ selected plants). Seeds of 100 self-pollinated plants were cultivated in Mid-April 2014 (Figure 2). Parameters such as yield, early ma-

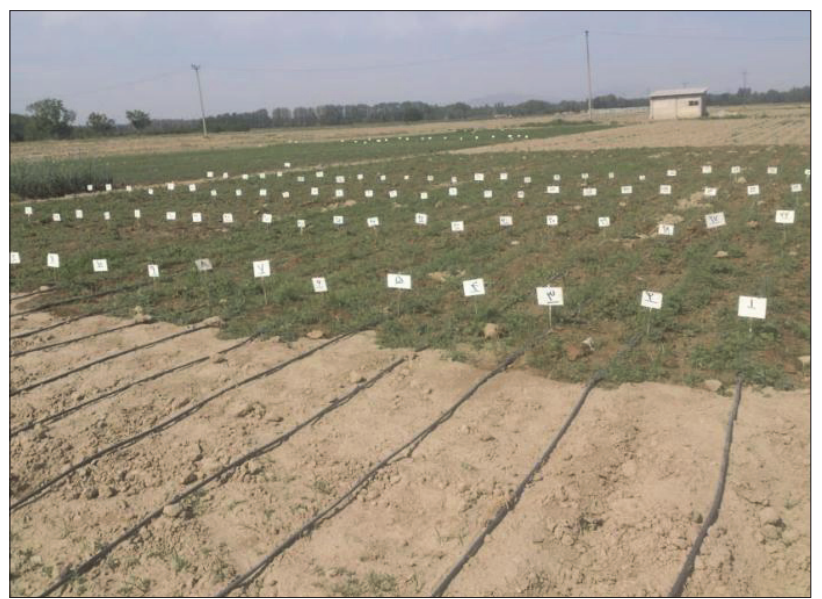

FIGURE 2. Culturing 100 families of 'Red Rey' cultivar for selection of superior families. 

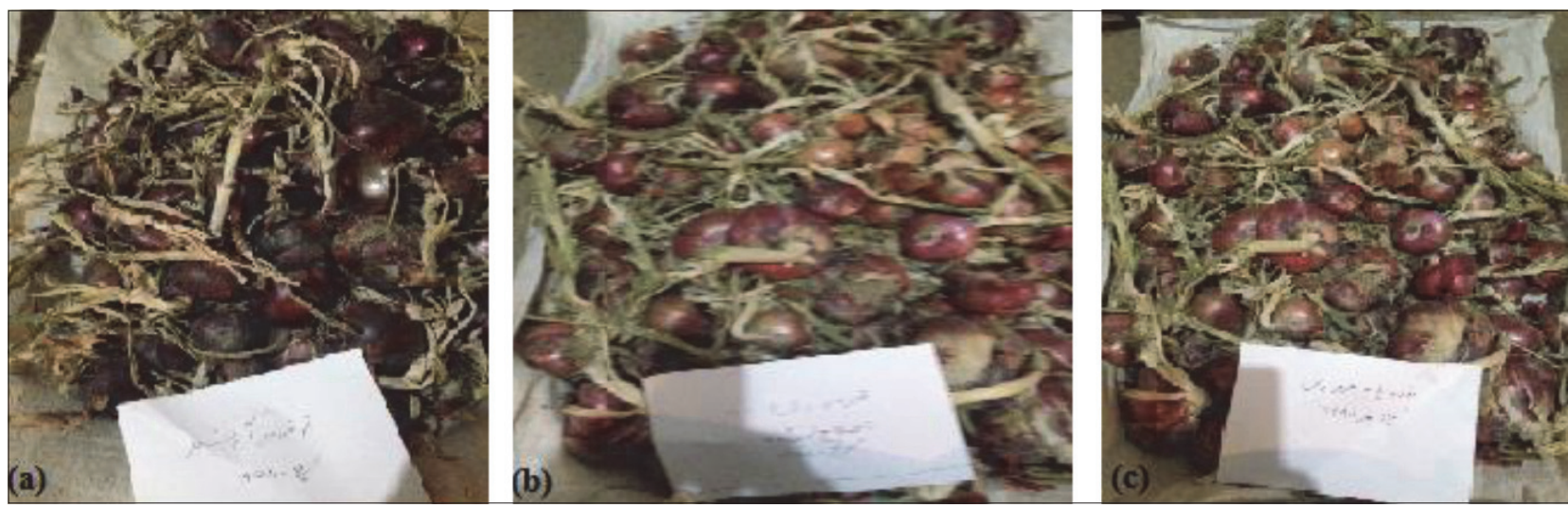

FIGURE 3. Samples of the harvested onion: 'Red Azar-shahr' (a), Modified mass 'Red Rey' (b), and 'Red Rey' base mass (c).

turity (ratio of dropping off plants) and bulb uniformity (shape, color, and without twins) were measured for these 100 families. The five best families were identified. Bulbs of the best selected families were harvested and stored until March 2014 and then planted in a 1,000 $\mathrm{m}^{2}$ field (March 2015).

At second stage, pollination occurred between plants in spring 2016; seed has been sown in July 2016, named as modified seed. Finally, modified seed along with primary seed (base population) and 'Red Azar-shahr' modified cultivar as a comparative were planted in completely random block design with three replications. Investigation of important breeding quantitative traits including growth traits [plant length (cm, by meter), leaf number per plant, neck diameter (by vernier caliper), weight (by digital scale), number of bulb centers and layer (by cutting 10 bulbs), percentage of twins]; yield, early maturity (ratio of dropping off plants) and bulb uniformity (shape, color and without twins) were calculated (Figure 3). The data were subjected to analysis of variance (ANOVA) and Duncan's test by SPSS 19.

\section{Results}

\section{Evaluated traits in $\mathbf{1 0 0}$ selected families}

To select the best families according to the ability of the studied breeding mass ('Red Rey') and in terms of the main and important traits desired in the project, objectives including yield, early maturity and bulb uniformity, shape and color were considered. Having the main traits among the studied families, cultivar 'Red Rey', i.e., semi-flat shape, light red color and narrow neck were figured out as the initial criteria for the supplementary study. Table 1 showed that genotype has significant effect on yield, early maturity and bulb uniformity at $1 \%$ level among 100 selfing families.

1. Yield. The results of mean of yield among 100 selected families revealed that the best families in terms of statistical rank of 68 and 94 with 75 and 72 tons ha- ${ }^{-1}$, respectively, and the lowest yield were observed in the family 6, 84 and 53 with 61 tons ha-1 (Table 2).

2. Early maturity. Comparison of the mean of data related to precocity among 100 families presented (Table 2), the top are 57 and 56 with 96.05 and $94.30 \%$, respectively.

3. Bulb uniformity. According to Table 2, the best number of bulb uniformity is number 6 with $93 \%$.

\section{Evaluated growth traits ('Red Rey' modified seed along with primary seed (base population) and 'Red Azar- shahr' modified cultivar population)}

The results of analysis of variance shown in Table 3 indicate that the effects of genotype are significant on plant height $(\mathrm{p}<0.01)$, percentage of twins $(\mathrm{p}<0.01)$, bulb weight $(\mathrm{p}<0.01)$, leaf number $(\mathrm{p}<0.05)$, bulb height $(\mathrm{p}<0.05)$, neck diameter $(p<0.05)$, yield, bulb diameter $(p<0.05)$, early maturity (ratio of dropping off plants) $(\mathrm{p}<0.01)$, and bulb uniformity at $1 \%$ level of significance. There is no significant difference between the genotypes in number of bulb center and layer. The results obtained was summarized as follows in Table 4.

1. Plant length. The results (Table 4) obtained in this study showed that plant height in the modified cultivar 'Red Rey' with $69.68 \mathrm{~cm}$ has a rank of "a" and the 'Red Azar-shahr' cultivar $(65 \mathrm{~cm})$ is in the same ranking but is superior to the base mass "b" with $54.67 \mathrm{~cm}$.

2. Number of leaves. It seems (Table 4) that the number of leaves in the modified cultivar 'Red Rey' has a rank of "a" with

TABLE 1. Analysis variance of the traits recorded in 100 pollinated families.

\begin{tabular}{lcccc}
\hline SOV & DF & Yield & Early maturity & Bulb uniformity \\
\hline Genotype & 99 & $248.28^{*}$ & $439.63^{*}$ & $357.21^{*}$ \\
Replication & 2 & $2.02^{\text {ns }}$ & $0.0026^{\text {ns }}$ & $0.09^{\text {ns }}$ \\
Error & 198 & 1.08 & 4.69 & 0.38 \\
CV & - & 2 & 2.86 & 1.86 \\
\hline
\end{tabular}

ns, ${ }^{*}$ and ${ }^{* *}$ indicates non-significant, significant at $P \leq 0.05$ and $P \leq 0.01$, respectively.

TABLE 2. Introduction of the top families in terms of yield, early maturity and uniformity of the bulb in 100 pollinated families.

\begin{tabular}{lcccccccc}
\hline $\begin{array}{l}\text { Family } \\
\text { no. }\end{array}$ & Uniformity (\%) & Rank & $\begin{array}{c}\text { Family } \\
\text { no. }\end{array}$ & $\begin{array}{c}\text { Early maturity } \\
(\%)\end{array}$ & Rank & $\begin{array}{c}\text { Family } \\
\text { no. }\end{array}$ & $\begin{array}{c}\text { Yield } \\
(\text { ton ha-1) }\end{array}$ & Rank \\
\hline 6 & 93.00 & a & 57 & 96.05 & a & 68 & 75.00 & a \\
- & - & - & 56 & 94.30 & ab & 94 & 72.00 & ab \\
\hline
\end{tabular}



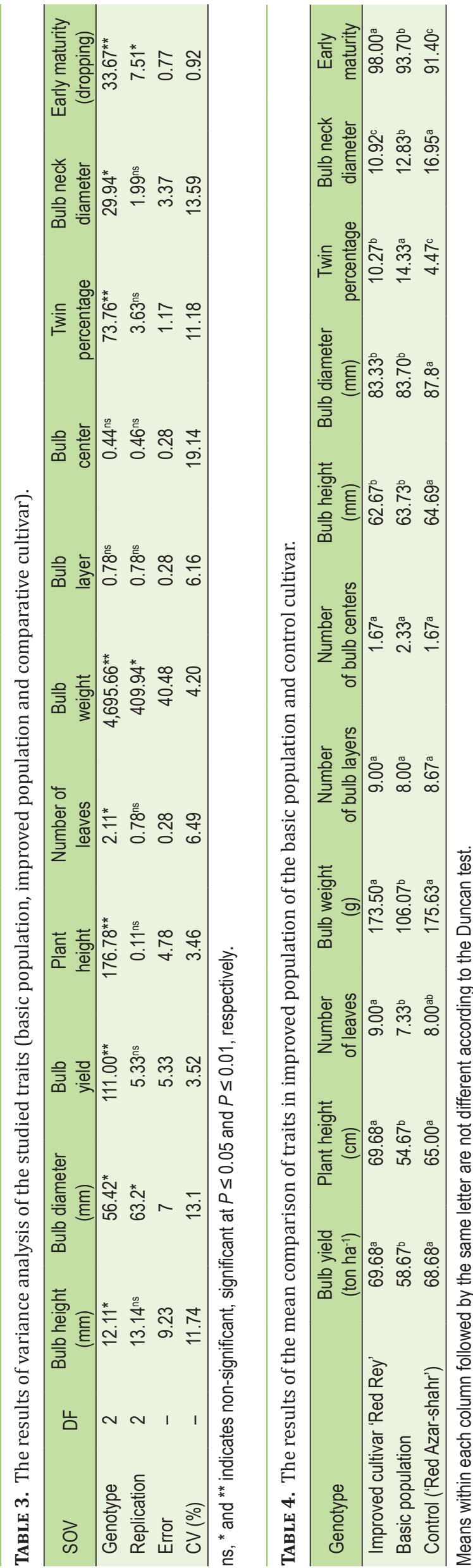

9 leaves and is in the same level with the 'Red Azar-shahr' cultivar but is better than the base mass. This trait with an average of 8 leaves in 'Red Azar-shahr' has the grade of "ab" and in the base mass " $b$ " with 7.3 number.

3. Dropping off plants. The results revealed (Table 4) that the early maturity and percentage of plants dropping off (about 15 days before harvest, at the end of irrigation) in the control cultivar with a "c" level of $91.4 \%$ has a minimum range. In the modified population, it has a superior priority of $98 \%$ and in the base population with $93.7 \%$, an average rank of "b"; so it can be said that a significant improvement has been made compared to the base population and 'Red Azar-shahr' cultivar (Table 4).

4. Yield. The Modified 'Red Rey' improved mass yield with 69.68 tons ha-1, has the highest rank of "a" compared to the base mass (with 58.7 tons with "b" ranking) (Table 4).

5. Bulbs height. The average height of bulbs according to the nature of 'Red Rey' mass in the base and modified mass are not significantly different and their rank is the same. 'Red Azar-shahr' cultivar (64.69 $\mathrm{mm}$ ) is slightly more elongated than 'Red Rey' cultivar (Table 4).

6. Bulb diameter. The bulb diameter (Table 4) showed that due to the nature of the shape in the 'Red Rey' mass (as in the bulb height attribute), the base and modified masses did not differ significantly and their rank was the same. However, 'Red Azar-shahr' cultivar has the highest rank of "a" with $87.8 \mathrm{~mm}$.

7. Bulb weight. It was observed that bulb weight in the modified 'Red Rey' mass with 173.5 g (grade "a") has improved compared to the base mass with $106.06 \mathrm{~g}$ ("b"). 'Red Azar-shahr' cultivar also showed "a” grade with $175.6 \mathrm{~g}$. (Table 4).

8. Bulb neck diameter. As shown in Table 4, the diameter of the neck indicated the highest rank " $c$ " with $10.92 \mathrm{~mm}$ in the modified mass compared to the base mass with $12.83 \mathrm{~mm}$ (rank "b"), i.e., the diameter of the neck has been reduced with the breeding. In 'Red Azar-shahr', the diameter of the neck has the most undesirable rank "a" with $16.95 \mathrm{~mm}$.

9. Percentage of twins. The results revealed that the percentage of twins (Table 4) in the base mass with 14.33\% demonstrated the rank of "a", but in the modified mass, the improved rank of "b" can be seen with $10.27 \%$. 'Red Azarshahr' is the best cultivar among the tested.

10. Layers and number of bulb centers. It should be noted that no significant difference was observed between the genotypes number of layers and number of bulb centers (Table 3).

\section{Discussion}

High yield, uniform and early maturity are important characters in bulb breeding. The results of this 5-year study of the experiments of Mousavizadeh et al. (2005), which took a total of eight years to identify the superior morphotype (No. 13). Success was achieved in total yield, reduction of neck diameter and relative early maturity.

Due to the severe heterozygosis in onions, accurate selections of bulbs of cultivars and bulks are approved to increase the quantitative and qualitative traits (Pike, 1986). This is also emphasized in the Dowker report (1990). On the other hand, according to the results, high heritability in traits such as yield or bulb weight was observed, which is in conformity with the results of Hosamani et al. (2010), Fasika et al. (2008), and Degewione et al. (2011).

In previous researches, mainly with mass selection, the desired genes were increased in masses such as 'Red Azar- 
shahr' (Mousavizadeh et al., 2005b) and 'Sefid Qom' (Noori Moghadam et al., 1999). The relative increase in total yield is similar to the above research. The results of the present study on the significant improvement of traits like single plant yield, plant height and number of leaves are also completely consistent with above findings.

One of the significant traits that are important in marketability is the diameter of the bulb neck. The corrective program reduced the numerical value of this trait in the modified population. Brewster (1987) reported that neck-thickness is a physiological disorder that is influenced by seasons, sites and cultivars. The onion yield has been increased in the improved population as mentioned. Genetic variability, character association pattern and direct and indirect effects of yield contributing characters are helpful in crop improvement (Chattopadhyay et al., 2013).

The yield modified 'Red Rey' mass was about 11 tons superior to the initial mass. In terms of neck diameter, the modified mass with $10.92 \mathrm{~mm}$ showed a significant difference compared to its original mass (with a diameter of $12.8 \mathrm{~mm}$ ) and with 'Red Rey' cultivar (16.95 mm). The percentage of dropping off plants 140 days after planting, which is considered as an indicator for early maturity, was $98 \%$ higher than the original mass of 'Red Rey' and its red cultivar, and there was a remarkable difference with them. In the study of Porta et al. (2014), bulbs used to develop S1 lines onion were selected for shape, colour and high number of skins. The original population and S1 lines were highly diverse for quantitative and qualitative traits. S1 lines were significantly different, with transgressive segregation for number and maximum leaf length, bulbing index, bulb weight, diameter, and dry matter content. Variances within S1 lines were greater than among S1 lines for all traits. Bulb colour and number of skins responded to selection. Heritabilities for dry matter and soluble solids were $52.6 \%$ and $36.1 \%$ respectively. Both traits were highly correlated. The development of S1 lines allowed the expression of genetic variation and the identification of better genotypes for agronomic traits of interest. Results of Rafipour et al. (2006) showed that selection had no significant effect on bulb yield and infected impure, thickneck (onions with thick and solid neck) and double bulbs. Significant differences (variations) were observed among genotypes for most of the measured characters. Among collected landraces, 'Kavar' was earlier and 'Tarom' was later in bulbing time. 'Yellow Sweet Spanish' and 'Tarom' showed the highest and lowest bulbing ratio, respectively. 'Kavar' and 'Tarom' had the lowest and highest percentage of thick-neck bulbs, respectively. 'Germes-e-Kazeroo' showed the highest yield, but was not significantly different from 'Sefid-e-Ghom', 'Germez-e-Azarshahr', 'Sefid-e-Abarkooh' and 'Yellow Sweet Spanish'. 'Yellow Sweet Spanish' and 'Sefid-e-Ghom' had the lowest and highest percentage of double bulbs, respectively. Bulbing ratio had a negative correlation with the number of days to onset of bulbing, the number of leaves per plant, and plant height. A positive correlation between bulb yield and plant fresh weight was observed as well. Based on cluster analysis, collected landraces were classified in three groups. Combined analysis for the three-year data (due to availability of the data from two previous years) showed that the highest bulb yield belonged to 'Sefid-e-Abarkooh'. Yield stability of this landrace was also higher than other landraces.

\section{Conclusion}

Finally, the modified population showed superiority over the original population and 'Red Azar-shahr' cultivar in the three above-mentioned traits. Unfortunately, in recent years, some important parental responsibilities have been forgotten. The genetic erosion of Iranian onion cultivars, which include at least more than 15 cultivars, has always caused weakness and reduced yield and undesirable bulb traits in these cultivars. It is necessary to maintain and improve the traits of these populations by implementing similar projects in this research. Failure to pay attention to this important issue will lead to the loss of the country's genetic resources and greater dependence on the import of expensive seeds from abroad. Therefore, one of the achievements of the present project was the genetic modification of 'Red Rey' mass and the aggregation and increase of genes effective in increasing yield as well as reducing the diameter of the bulb neck and, of course, creating relative early maturity.

\section{References}

Abayneh, M. (2001). Variability and association among bulb yield, quality and related traits in onion (Allium cepa L.). M.Sc. thesis (Alemaya University, School of Graduate Studies).

\section{Anonymous. (2013). FAO Yearbook. www.fao.org. FAOSTAT.}

Anonymous. (2015). Agricultural Statistics Vol. I: Crop Products. Crop Year 2012-13 (Ministry of Jihad-e-Agriculture, Assistance of Economic Planning, ICT Center), p. 92.

Brewster, J.L. (1997). Onion and garlic. In The Physiology of Vegetable Crops, H.C. Wien, ed. (U.K.: CAB Int.), p. 581-619.

Chattopadhyay, A., Sharangi, A.B., Dutta, S., Das, S., and Denre, M. (2013). Genetic relatedness between quantitative and qualitative parameters in Onion (Allium cepa L.). Vegetos 26(1), 151-157. https://doi.org/10.5958/j.2229-4473.26.1.021.

Darabi, A.S. (2005). Improvement of local onion in Behbahan by the method of producing pollinator free cultivars. Final Report of Khuzestan Agricultural and Natural Resources Research Center. p. 12.

Degewione, A., Alamerew, S., and Tabor, G. (2011). Genetic variability and association of bulb yield and related traits in shallot (Allium cepa var. aggregatum Don.) in Ethiopia. Int. J. Agric.Res. 6(7), 517-536. https://doi.org/10.3923/ijar.2011.517.536.

Dowker, B.D. (1990). Onion breeding. In Onions and Allied Crops, Vol. 1, H.D. Rabinowith, and J.L. Brewster, eds. (Boca Raton: CRC Press Inc.).

Dowker, B.D., Horobin, J.F., Crowther, T.C., and Fennell, J.F.M. (1984). Breeding of improved open-pollinated populations of springsown onions. J. Agric. Sci. 102, 615-625. https://doi.org/10.1017/ S0021859600042167.

Fasika, S., Hailu, T., and Kebede, W. (2008). Genetic variability studies in Ethiopia Shallot. East. South Afr. J. Sci. 2, 130-134.

Goldschmied, P., Ellerbrock, R., Cobb, E., and Mutschler, M. (2004). Proceeding of creation and testing of true synthetic varieties of onion (Allium cepa L.). National Allium Research Conference, p. 69.

Havey, M.J., and Randle, W.M. (1996). Combining abilities for yield and bulb quality among long- and intermediate-day open-pollinated onion populations. J. Am. Soc. Hortic. Sci. 121, 604-608. https://doi. org/10.21273/JASHS.121.4.604.

Hosamani, R.M., Patil, B.C., and Ajjappalavara, P.S. (2010). Genetic variability and character association studies in onion (Allium cepa L.). Karnataka J. Agric. Sci. 23(2), 302-305.

Jones, J.A., and Mann, L.K. (1963). Onion and their Allies (New York: Leonard Hill), p. 28.

Kalloo, J.C., Pandey, S.C., Lal, S., and Pandita, M.L. (1982). Correlation and path analysis studies in onion (Allium cepa L.). Haryana J. Hortic Sci. 11, 97. 
Khodadadi, M., and Rastegar, J. (1999). Study growth pattern and yield of several cultivars and populations of Iranian onion based on physiological indicators. Seedlings and Seeds 4(24), 659-675.

Manbachi, M., and Khodadadi, M. (2011). Study yield, yield components and some qualitative traits in 23 Iranian onion populations. M.Sc. thesis (Tehran: Islamic Azad University, Science and Research Branch).

Mousavizadeh, S.A., Moghadam, M., Torchi, M., Mohammadi, A., and Masiha, S. (2006a). Morphological and agronomic diversity of indigenous Iranian onion populations. Iran J. Agric. Sci. 2, 193-202.

Mousavizadeh, S.A., Moghadam, M., Torchi, M., Mohammadi, A., and Masiha, S. (2006b). Genetic variation of indigenous populations of onions in Iran using RAPD markers. J. Agric. Sci. 16(1), 265-277.

Noori Moghadam, R., Mirzai Qaryeh, Y., and Shahriari, A. (1998). Determine and introduce the most suitable onion cultivars for cultivation in special regions of the country. Final report of research project, Seed and Plant Improvement Institute.

Pike, L.M. (1986). Onion breeding. In Breeding Vegetable Crops, M. Bassett, ed. (AVI Publishing Co.), p. 357-394.

Porta, B., Rivas, M., Gutiérrez, L., and Galván, G.A. (2014). Variability, heritability, and correlations of agronomic traits in an onion landrace and derived S1 lines. Crop Breeding Appl. Biotechnol. 14(1), 29-35. https://doi.org/10.1590/S1984-70332014000100005.

Rafipour, M., Masiha, S., Motalebi Azar, A.R., and Mobli, M. (2006). Evaluation of yield and relationships between some characteristics of onion (Allium cepa L.) in nine Iranian landraces. J. Agric. Sci. 15(4), 211-225.

Received: Oct. 27, 2020

Accepted: Feb. 5, 2021

Addresses of authors:

Sayyedeh Mahsan Taghi Shokrgozar ${ }^{1}$, Mohsen Khodadadi ${ }^{2}$, Vahid Abdossi ${ }^{1}, *$, Vahid Zarrinnia ${ }^{3}$ and Ramin Hajiyanfar ${ }^{2}$

${ }^{1}$ Department of Horticultural Sciences, Islamic Azad University, Science and Research Branch, Tehran, Iran

${ }^{2}$ Vegetable Research Centre, HSRI, Agricultural Research Education and Extension Organization, Iran

${ }^{3}$ Department of Plant Protection, Science and Research Branch, Islamic Azad University, Tehran, Iran

*Corresponding author; E-mail: abdossi@yahoo.com 